\title{
The Psychic Life of Gender
}

\author{
Introducing a psycho-soma-technical \\ approach to gender
}

\author{
an interview with co-editor of the Somatechnics Journal \\ and Professor Sheila L. Cavanagh, from the Department \\ of Sociology at York University in Toronto, Canada
}

SHEILA L. CAVANAGH is a professor at York University, Toronto. She coordinated the Sexuality Studies Program at York (2010-2014) and is past chair of the Sexuality Studies Association (Canada) (2014-2016). Cavanagh also co-edited the Somatechnics Journal (2016-2018). Her research is in the area of psychoanalytic sociology, gender and sexuality studies. Cavanagh edited a special double issue of Transgender Studies Quarterly on psychoanalysis (2017) and is completing her third book monograph titled Transgender and the Other Sexual Difference: Jacques Lacan and Bracha L. Ettinger. Cavanagh co-edited Skin, Culture and Psychoanalysis (2013) and her first sole-authored book titled Sexing the Teacher: School Sex Scandals and Queer Pedagogies (2007) was given honorable mention by the Canadian Women's Studies Association. Cavanagh's second sole-authored book titled Queering Bathrooms: Gender, Sexuality, and the Hygienic Imagination (2010) is a GLBT Indie Book Award finalist and recipient of the CWSA/ACEF Outstanding Scholarship Prize Honourable Mention (2012). Her performed ethnography titled Queer Bathroom Monologues premiered at the Toronto Fringe Festival (2011) and was given the Audience Pick Award. The play was professionally staged at Buddies in Bad Times Theatre, Toronto (2014) and has toured at conferences, colleges and universities in Canada and the United States. Lastly, Cavanagh has published in a wide range of international journals and given keynotes addresses at conferences in Sweden, Turkey, the United States and Canada.

Both assistant professor CAMILLA BRUUN ERIKSEN and associate professor MICHAEL NEBELING PETERSEN are part of the FKK-funded project Medicine Man, which explores how everyday cultures and perceptions of middle age men's bodies unfold when masculinity is increasingly both mediatized and medicalized. Today large parts of intimate life, health and social relations have become mediatized: Bodies are monitored using mobile apps, communities are formed on social media, and intimate questions are increasingly the topic of TV-shows and intensified in online campaigns. Medicine Man is based on a theoretical framework of somatechnics and assemblage theory. The project considers medicalization as a cultural phenomenon, which emerges inseparably from contemporary media, and thus adds humanistic research to health and social sciences about how mediatized culture shapes the body and its medicalized interventions. 
In the tradition of feminist posthumanist theories, somatechnical theories invite us to think about how technologies are always already enfleshed, and how bodies are always already technologized. In a queer theoretical tradition, and forefronting trans studies, crip and critical disability studies help us to understand how all bodies are modified and assembled through and in technologies. In this way, somatechnics centers the technological parts of becoming, not in opposition to 'natural' becoming, but rather in ways that challenge oppositions such as nature and culture, human and machine. In the Spring of 2019, the research project Medicine Man - media assemblages of medicalized masculinities had invited scholars to participate in a seminar in order to discuss and develop somatechnical conceptualizations of masculinity in relation to even more intensified contemporary medicalizations and mediatizations of gendered being and embodiment. From this perspective, masculinities do not derive from certain bodies nor genes, rather, masculinities are an ongoing dynamic process in which bodies come into being. Following Butler, we understand this process as a performative and ritualized doing which constitutes and fixates bodies, genders, and sex. However, we are curious as to how this process of gendered embodiment also involves technological and medical interventions: How masculinities are being reconfigured, recalibrated, and reassembled in meetings between the material and affective presence of a body, gendered regulatory and disciplinary power technologies, prosthetic and surgical interventions, and medical treatments and diagnoses within an intensified mediatized presence. As part of the seminar, Sheila L. Cavanagh insisted on bringing psychoanalysis (back) into the center of somatechnical queer studies and so Camilla Bruun Eriksen and Michael Nebeling Petersen conducted an interview in order to better understand the inner workings of psychoanalysis within gender theory in a somatechnical framework.

SHEILA I really like the somatechnical approach to theorizing masculinities. One of the many valuable things the soma-technical has to offer is that it encourages us to think critically about bodies on multiple levels - and by bodies I am not only referring to biology, but to embodiment. Our bodies are shaped by phenomenological sensations, desires, affects and a myriad of technological assemblages well theorized in somatechnical terms. Bodies are wonderfully diverse and hybrid. The somatechnical approach to bodies is attentive to the way human experience is mediated by organic and technological assemblages that confuse and confound nature/culture binaries. The somatechnical approach to theorizing embodiment is of central importance to transgender studies which, in my mind, includes critical masculinity studies (among other things), because it enables us to understand the way sex and gender is subject to change. One can be a feminine man or a masculine woman and somatechnics gives us a way to understand the way sex and gender are not co-determinate but mediated by a range of factors specific to culture, technology, politics, discourse, power, ability and so forth.

Queer theory teaches us that gender is not simple, and I like the way somatechnics gives us a way to navigate and to express the complexities central to everyone's gender identity regardless of trans- status. I am excited by the points of intersection between critical masculinity studies and somatechnics. In addition to the incredible project you are doing on Medicine Men: Media Assemblages of Medicalized Masculinity at the University of Southern Denmark, I want to briefly mention the paradigm-shifting work of Dan Irving, a Canadian scholar at the University of Ottawa in Canada. His research program investigates what it means to be a 'self-made man' in trans- experience. Specifically, he asks important questions about the way neoliberal discourses shape our understanding of what it means to transition for many trans- men in the North American context. Irving considers how many embodied narratives of transition are dependent upon white, class-specific, able-bodied presumptions about what it means to be a 'real-man' and the political implications for critical masculinity studies. What I like about his work is that it enables us to expand our thinking about what it means to be a man and masculine beyond 
hegemonic notions of male-masculinity saturating popular discourses of gender. The strength of the somatechnologically informed approach to masculinity studies is that it prompts us to broaden our understanding of what it means to be a body, to be gendered and sexual in the contemporary landscape.

CAMILLA How does soma-techniques trouble or disturb binaries in a way that e.g. queer theory doesn't? Or maybe how does somatechnical theory do it differently?

SHEILA Somatechnics is, in my view, grounded in queer theory. Scholars like Malena Gustavson, Samantha Murray, Holly Randell-Moon, Karin Sellberg, Elizabeth Stephens, Susan Stryker, Nikki Sullivan, Iris van der Tuin and myself who are central to the formation of the field are all, in various and different ways, engaged with queer theory. Queer theory gives us a way to understand gender trouble in Butlerian terms, power-knowledge relations and bio-politics in Foucauldian terms and the epistemology of the closet in ways so beautifully narrated by Eve Kosofsky Sedgwick. More recent queer of color critique has pushed us to better understand histories of colonization, migration, nationalism, citizenship and systems of racialization in relation to sexuality and gender formation, and I am thinking here of scholars such as David Eng, Gayatri Gopinath, José Estaban Muñoz, Rinaldo Walcott.

I view somatechnics as an outgrowth of queer theory but with a Deleuzian and Guattarian twist. While every somatechnical scholar will have a different take on the history and theories central to the development of the field, I believe there is great inspiration taken from work such as Capitalism and Schizophrenia: Anti-Oedipus (1972) and $A$ thousand Plateaus (1980) by Deleuze and Guattari; Frankenstein by Mary Shelly and the incredible work on monster theory, queer crip theory, and abjection stemming from it. I would also mention A Cyborg Manifesto: Science, Technology and Socialist Feminism in the late 20th Century by Donna Haraway, On Touching by Jean Luc Nancy, and transgender studies scholarship pioneered by scholars like Aren Z. Aizura, Susan Stryker, Sandy Stone, Paisley Currah, Stephen Whittle and many others.

If, as Jay Prosser argued in Second Skins: The Body Narratives of Transsexuality, queer theory has neglected questions of embodiment, technology and phenomenology, somatechnics seeks to incorporate the fleshy-sensory-technologically mediated aspects of embodiment into its theorizing. We might say that somatechnics is a late (post)-modern approach to body studies whereby we, who publish in the field or identify with the field, are 'polyamorous thinkers'. We refuse to be bound to any one disciplinary distinction, theoretical influence or paradigmatic boundary. As such, somatechnics is inter- and multi-disciplinary, but also deeply concerned about questions of life, sociality, feeling, technology and what will become of our futures.

Speaking of futures, I would like the field of somatechnics and contemporary queer theorists more generally, to engage more seriously and consistently with psychoanalysis. If we are going to truly trouble binary oppositions and the exclusions they engender, we need to engage important questions relating to unconscious processes and the way they confound any simple identitarian notion of what it means to be human. Contemporary queer theorists often forget -or intentionally overlook - the contributions that psychoanalysis makes to the field. Judith Butler's writing on gender melancholia engage Freud's early writings on mourning and melancholia; Eve K. Sedgwick's work on queer affects is inspired by Melanie Klein and Silvan Tomkins; Lee Edelman's work on male homoeroticisms is heavily influenced by Jacques Lacan's writing on jouissance, a form of a painful pleasure. Queer of color scholarship also engages psychoanalysis. José Esteban Muñoz (1967 2013) wrote about feeling brown/feeling down in terms of the depressive position theorized by Melanie Klein; David Eng writes about racial castration in Freudian terms; Amber Jamilla Musser writes on race, power and masochism and the list goes on. What strikes me as original and important about these queer scholarly engagements with psychoanalysis is that they attend to those 
elements of subjectivity relating to gender, race and sexuality that are not conscious or self-evident. In psychoanalytic terms, we are internally divided between conscious and unconscious elements of our being. Identity-based theorizing cannot account for dualities, ambiguities and contradictions within the subject.

In my mind, psychoanalysis underpins some of the most important innovations in queer theorizing. But the psychoanalytic bits are usually forgotten or ignored in the secondary source literature and this is a great loss. When gender and sexuality studies are infused with psychoanalytic insights into desire, we are able to think in more robust ways about what Judith Butler calls the psychic life of power. If we want to understand the tenacity and reproduction of binary gender codes governing masculinity and femininity, for example, we must consider our passionate attachments to gender norms. Unlike symbolic interactionists like Erving Goffman, who wrote about gender as a performance, Butler understood that gender is something more than a conscious performance hence her theorization of gender performativity. The theory of gender performativity is a queer retelling of the Freudian Oedipal complex whereby what is at stake is not only the prohibition of incest, but the prohibition on same-sex love. Gender is not only a performance. It is a way to manage the prohibition on homosexuality by making unconscious compromises: if I cannot love my father (as a boy), I will grow up to be like him (incorporate masculinity by way of identification); if I cannot love my mother (as a girl), I will grow up to be like her (incorporate femininity by way of identification). Butler's theorization of gender trouble does not make sense without attention to unconscious processes. As a queer theorist who engages psychoanalysis, I believe that gender is psychically significant. I also believe that somatechnical studies of gender, sexuality and the body can all be enriched by attention to what I would like to introduce as the psycho-soma-technical approach.

MICHAEL What is a psycho-soma-technical approach to gender?
SHEILA In my view, the psycho-soma-technical approach to gender combines the insights of somatechnics with critical psychoanalysis or, in more specifically sociological terms, psychosocial studies. In other words, psychosomatechnical studies involves attention to unconscious processes and to core writings in the field of psychoanalysis. Psychosomatechnics critically incorporates psychoanalytic theories of the body, psychosexuality, the unconscious life of the subject, symptomatology, and so on, into accounts of embodiment.

I always tell my graduate students that the first truly queer text was Three Essays on The Theory of Sexuality by Sigmund Freud. For me, this is a queer text par excellence! I am not suggesting that Freudian psychoanalysis is above critique, but that Freud took human sexuality including its unconscious elements seriously and understood the problem of normativity central to modernity. He dared to talk about infantile sexualities, animal sexualities, perversions, non-genital erotic zones, clitoral orgasms, unconscious phantasies, etc., all in the Victorian era when it was not popular to do so. No one overturned sexual taboos and the silence surrounding sexuality in the way that Freud did. He troubled the binaries between male and female, masculine and feminine, heterosexual/homosexual, etc., long before queer theory was institutionalized as a field of study. Freud's foundational premise was that we are inherently bisexual and polyamorously perverse. A critically queer reading of Freud offers a solid groundwork for a radical gender and sexual politic responsive to the unconscious life of the subject. Although Freud's work is often misread and he is, unfairly in my view, called a biological determinist he never lost track of the socio-cultural realm. He wrote extensively about the effect of civilization on what he called - in scare-quotes - the 'natural' sexual instinct. As a psychoanalyst, he was deeply concerned about how the repressive mechanisms of culture disproportionately effected women.

I will leave aside what I take to be Freud's contributions to psychoanalytic feminisms, and briefly comment on his contributions to queer theorizing and gender studies. In Three Essays on the Theory of Sexuality Freud claims that we overvalue 
the object of attraction (man or woman) and undervalue the aim meaning the sexual act and its unconscious significance. Moreover, we understand sexuality in terms of its manifest and adult heterosexual expression. We forget that sexuality is, almost by Freudian definition, lifelong, perverse and bisexual. When you introduce unconscious processes into sexuality studies, heterosexuality and homosexuality are not what they seem. There is always an underside, another parallel scene that confounds sexual orientation in the psychoanalytic frame. What may appear to be a heterosexual object choice conceals a homoerotic aim and vice versa. Sexuality, in psychoanalytic perspective, conceals or is, rather, driven by non-conscious and unconscious instincts. What Sedgwick calls the epistemology of the closet is not (only) a site of repression whereby gays, lesbians, bisexuals, etc., are closeted, but a space of unconscious possibility where something non-conscious and forbidden can be expressed.

In Queering Bathrooms: Gender, Sexuality and the Hygienic Imagination (2010) I tried to understand the way bi-gender toilet designs are not only oppressive sites of transphobic hate, but homoerotic spaces. I could go on but suffice to say that what psychoanalysis offers to somatechnics is an insistence that our sexuality like our gender is not straightforward. Identities are, in other words, defenses against difference both internal and external. By this I mean that identities are only the tip of the proverbial iceberg. Identities refer to what we avow or take to be true about ourselves and others. Although identities have been strategically important for LGBTQ activism, they conceal elements of our being that confound categorization or language more generally. In this way we are all, to use Julia Kristeva's often cited book title, Strangers to Ourselves. There is so much about who we are that we do not know. I often wonder what we would write, in the name of somatechnics, if we didn't foreground identity but engaged unconscious processes?

I would also like to say that I endorse critical approaches to psychoanalysis, not psychoanalytic dogma or conservativism. Psychoanalysis is, in my view, at its best when it throws what counts as 'normal' into question. Let us remember that Freud was the first one to place quotation marks around the word 'normal' in his writing on sexuality. Normality is impossible - and overrated! Our psychopathologies are what make us human and this is, in my view, a wonderfully queer approach. See, for example, Clinical Encounters in Sexuality: Psychoanalytic Practice \& Queer Theory edited by Noreen Giffney and Eve Watson. This collection brings psychoanalysis and queer theory into conversation. I would love to see a collection brining somatechnics into conversation with psychoanalysis. Until such a collection is edited, suffice to say that there is an unconscious life to gender and sexuality worthy of somatechnical investigation. By bringing psychoanalysis to the somatechnical table so to speak, we can envision bodies and technologies in relation to psychic life.

MICHAEL What I have taken from the field of somatechnics and other posthuman theorizations of embodiment is the acknowledgement that the somatechnical body isn't a new one - the human has always intervened in his body?

SHEILA And you are right. Like you, I am not one of those people who believes our experiences of embodiment today are somehow more complex or elaborate than they were in the past. Certainly, we have always found ways to modify our bodies. Scarification and tattooing, for instance, have been around for ages. In fact, we can't properly think about the body or embodiment without attention to history; personal histories and cultural histories. I think with the emergence of cultural studies and soma-technics we have a growing understanding of the fact that the body is a very complex interplay between nature and culture. In fact, the psyche may be the product of an alchemy between nature and culture.

CAMILLA Which I guess, brings us to the ever-haunting question of the binary?

SHEILA Yes! I think, we are witnessing a proliferation of gender identifications that defy bi-gender culture. People are identifying as bi-gender, 
a-gender, non-binary and so on. People are also adopting gender pronouns that include 'they,' 'them' and 'their' among many other terms of address. I have great respect and admiration for people who are navigating ways to be, and to self-identify, outside the gender binary. It is vitally important to support gender self-determination and to respect gender identity and pronoun choice. In fact, this is a civil rights issue as the horrific trans-bathroom bans in the United States demonstrate. Most readers of somatechnics know and acknowledge this transphobic reality. But what I think we don't acknowledge is the way the gender binary does not sufficiently capture anyone's experience. None of us live our lives as stereotypes and it is not possible to conform absolutely to masculine and feminine gender codes; even if there was some provisional agreement about what it might mean to be a man or a woman - which of course there is not. No gender identity, trans- or cisgender, can capture all of what is determinative of our experience as subjects. If we are all, to borrow Freud's term, polyamorously perverse, and have bisexual capacities and inclinations in the psychoanalytic sense, gender identities and sexual orientations are misleading and reductive. They may be fictions essential to life and survival, but they detract attention away from the internal contradictions central to our being.

A somatechnical engagement with psychoanalysis would, ideally, enable us to think beyond binaries. Take, for instance, Freud's writing on the bodily ego (which involves the way we come to inhabit our bodies instinctively, sexually and phenomenologically). Or Jacques Lacan's writing on the mirror stage. These psychoanalytic formulations enable us to consider how our sense of self is shaped in relation to Others, that is intersubjectivity. No identity takes shape without a relation - internal and external - to an Other - as person or as object. We see ourselves through the mirror image or the eyes of an/Other. As Kaja Silverman says, there are also acoustic mirrors central to our experiences in utero that shape object relations. Theories of gender, sexuality and embodiment must come to terms with the fact that human experience is complicated by intersubjectivity (relations with Others), and intrasubjectivity (relations with internal Others as objects). While we use language, identifications and gender pronouns to produce a semblance of order, human experience is dynamic and irreducible to any given term of reference. Embodiment is complicated. Somatechnical studies of body modification practices such as tattooing, scarification, piercing, etc. have been of vital cultural significance.

I am equally impressed and inspired by theorizations of skin, technology and bodily transformations in somatechnical research. But I always wonder how somatechnical research would be enhanced with attention to unconscious processes. I believe we should engage psychoanalysts who work with clients because they are attuned to unconscious communications. We do fascinating things with the surfaces of our bodies, our skins, etc., but what do these surface inscriptions, cuts and grafts signify for others and for ourselves? Likewise, what does a gender identity investment in masculinity, femininity, a combination or refusal thereof, tell us about a particular subject? We know there are differences between people identifying with a given gendered position, but when we take unconscious processes seriously those differences grow exponentially and can be understood in sexually specific ways. To the extent that we negate unconscious processes, we miss so much of vital importance to gender, sex and body studies.

MICHAEL So, we really should start paying more attention to psychoanalysis?

SHEILA Yes, I think we should all read psychoanalysis, but critically and with attention to our own internal resistances! One of the things psychoanalysis teaches us is that there is a lot we don't want to know about ourselves and others. But, at the same time, psychoanalysis has been used in conservative, diagnostic and normalizing ways - I am deeply troubled by the way some psychoanalysts think it is there job to 'cure' or to 'fix' someone. In my own psychoanalytically informed sociotherapy practice, I do not begin with the premise that people are sick or disordered. In my 
view, psychoanalysis should involve critical and self-reflective dialogue. Analysts should respect the wisdom of the symptom - not try to eradicate or cure it! I believe in minimizing suffering yes, but our idiosyncratic quirks, our symptoms, give us insight into who we are. Symptoms index the compromises we have made to survive - to live and to love and to lose. From an academic perspective, psychoanalysis can help us understand gender as a symptom. If masculinity and femininity are symptoms, what can they teach us? It is not enough to catalogue what counts, culturally and historically, as masculine and as feminine, but to better understand our passionate attachments to gender - whatever those genders might be. Gender needs to be taken seriously, like a symptom it needs to be respected and interpreted with a critical psychoanalytic attunement to what it inscribes about the history of the subject. 